defined by a body mass index $(\mathrm{BMI}) \geq 30$. Functional impairment was assessed by the Womac index and Lequesne index.

Results: The study included 186 patients. There were 31 males and 155 femmes. The mean age was $60 \pm 10$ years. The percentage of obese patients was $53,8 \%$. The mean age was similar in both groups obese and non obese. There were more women in the obese group compared to the non obese group $(\mathrm{p}=0.0001)$, more patients who had diabetes mellitus and dyslipidemia ( $p=0.002$ ). Non-obese patients had a shorter duration of symptoms with no statistical significance $(p=0.151)$. Obese patients had more involvement of both knees $(p<0.0001)$. Obesity did not have an impact on pain severity. Severity of radiological images $(p=0,0001)$ were more frequent in obese patients. Functional impairment was similar in both groups. However, the percentage of patients having a very important functional impairment with Lequesne index was higher in obese patients $(p<0.029)$. Obese patients also needed more physical therapy sessions $(p=0.035)$.

Conclusion: Knee osteoarthritis in obese patients is characterized with the femlae gender predominance, bilateral knee involvement, and a more severe images on radiographs. Thus the need for better control of weight and the importance of physical activity.

REFERENCES:

[1] Coggon D, Reading I, Croft P, et al. Knee osteoarthritis and obesity. Int J Obes Relat Metab Disord J Int Assoc Study Obes 2001; 25: 622-627.

Disclosure of Interests: None declared

DOI: 10.1136/annrheumdis-2021-eular.3602

\section{POS1282 VERIFICATION OF MANIFESTATIONS OF SARCOPENIA IN OBESE PATIENTS WITH THREE METHODS FOR BODY COMPOSITION ASSESSMENT}

V. Vasileva ${ }^{1}$, L. Marchenkova2, V. Sergeev2. ${ }^{1}$ National Medical Center for Rehabilitation and Balneology, Department of Somatic Rehabilitation, Reproductive Health and Active Longevity, Moscow, Russian Federation; ${ }^{1}$ National Medical Center for Rehabilitation and Balneology, Department of Somatic Rehabilitation, Reproductive Health and Active Longevity, Moscow, Russian Federation

Background: With new technologies for body composition assessment determining changes learn, muscle and fat mass. Prevention of sarcopenic obesity is timely detection of decrease.

Objectives: Aim of the study was to compare the effectiveness of three methods of body composition assessment such as bioimpedans analysis (BIA), air-replacement bodyplatismography (BodPod) and Dual X-ray absorptiometry Total body program (DXA Total Body) in the verification of reducing of skeletal muscle mass as sign of sarcopenic obesity in obese patients.

Methods: The study group included 95 patients aged 21-69 y.o. (average age $53,9 \pm 11,05$ years) with $\mathrm{BMl} \geq 30.0 \mathrm{~kg} / \mathrm{m} 2$. The control group included 37 patients aged $37-69$ y.o (average age $50,73 \pm 10,6$ years) of the same age without obesity with BMI 20.0-29.9 kg/m2. Body composition was tested using BIA, BodPod and DXA with calculating fat, lean and skeletal muscles mass $(\mathrm{kg})$ and \% in all the patients.

Results: According to BIA the groups differ only in fat mass (FM) $42.75(4.8 ; 6.3)$ vs. $33.15(28.4 ; 35.5) \mathrm{kg} ; \mathrm{p}=0.036$ and did not differ ( $p>0.05$ ) in lean (LM), skeletal muscle mass (SMM) and in \% of FM and SMM. According to BodPod analyses groups differed in the FM $3.4[36.81 ; 69.94]$ vs $31.02[23.22 ; 38] \mathrm{kg}, \mathrm{p}=0.007, \%$ FM $45.4[42.1 ; 53.8]$ vs 37.7 [28.6;41.1], $p=0.003$ and $\%$ LM - 54.6 [46.2;57.9] vs 62.3 [58.9;71.4], $p=0.003$, but had statistically equivalent values of LM $55[49.48 ; 67.77]$ vs $40.36[33.12 ; 49.06]$ $\mathrm{kg}, \mathrm{p}=0.19$. According to DXA Total Body analyses statistically significant differences $(p<0.05)$ have been identified between the groups in FM and \% FM of the hands, feet, trunk, total body ( $p>0.05)$, but not in LM and \% LM $(p>0.05)$ (Table 1$)$.

Table 1. Effectiveness of three methods for body composition assessment

\begin{tabular}{lccc}
\hline INDICATORS & STUDY GROUP & CONTROL GROUP & $\mathbf{p}$ \\
\hline Weight $(\mathrm{kg})$ & $106[96 ; 122]$ & $80[77 ; 81]$ & 0.00251 \\
BMI $(\mathrm{kg} / \mathrm{m} 2)$ & $37.6[104 ; 124]$ & $26.8[24 ; 30]$ & 0.000000 \\
Bod Pod & & & \\
$\%$ fat mass & $45.4[42.1 ; 53.8]$ & $37.7[28.6 ; 41.1]$ & 0.003424 \\
$\%$ lean mass & $54.6[46.2 ; 57.9]$ & $62.3[58.9 ; 71.4]$ & 0.003424 \\
fat mass $(\mathrm{kg})$ & $43.4[36.81 ; 69.935]$ & $31.016[23.223 ; 38.004]$ & 0.006836 \\
lean mass $(\mathrm{kg})$ & $55.002[49.48 ; 67.77]$ & $40.359[33.122 ; 49.058]$ & 0.185377 \\
BIA & & & \\
fat mass $(\mathrm{kg})$ & $42.75[4.8 ; 6.3]$ & $33.150[28.4 ; 35.5]$ & 0.035771 \\
lean mass $(\mathrm{kg})$ & $59.5[53.95 ; 71.05]$ & $54.850[49.9 ; 62.6]$ & 0.458312 \\
skeletal muscle mass $(\mathrm{kg})$ & $27.9[23.9 ; 33.2]$ & $25.6[22 ; 29.3]$ & 0.701678 \\
skeletal muscle mass $(\%)$ & $45.3[43.3 ; 47.7]$ & $47.1[42.3 ; 48.1]$ & 0.415687 \\
DXA Total Body & & & \\
total body lean mass $(\mathrm{g})$ & $97276[86062 ; 109154]$ & $62628[57839 ; 85068]$ & 0.602523 \\
total body fat mass $(\mathrm{g})$ & $47030[39300 ; 56729]$ & $25652[22164 ; 36396]$ & 0.009796 \\
total body muscle mass $(\mathrm{g})$ & $49861[42793 ; 57088]$ & $36426[32273 ; 43341]$ & 0.973711 \\
\hline
\end{tabular}

Conclusion: From methods of body composition assessment, air-replacement bodyplatismography (BodPod) is the most sensitive in the verification of skeleta muscle mass reduction in obese patients. This method shows that patients with obesity have a significantly reduced muscle mass compared with normal weight or overweight subjects.

\section{REFERENCES:}

[1] L. A. Marchenkova, V. A. Vasileva, Motor and balance function disorders and possibilities of their correction in patients with obesity and metabolic syndrome // Lechashchiy vrach. 2019. № 4. S. 68.

[2] P. Corbeil, M. Simoheau, D. Rancourt, A. Tremblay, N. Teasdale, Increased risk for falling associated with obesity: mathematical modeling of postural control // IEEE Transactions on Neural Systems and Rechabilitation Enqineering. 2001; 9 (2): 126-136.

Disclosure of Interests: None declared

DOI: 10.1136/annrheumdis-2021-eular.3629

\section{POS1283 SPONDILODISCITIS WITHOUT DOCUMENTED GERM: WHAT THERAPEUTIC MANAGEMENT?}

R. Grassa ${ }^{1}$, N. El Amri ${ }^{1}$, K. Baccouche ${ }^{1}$, S. Lataoui ${ }^{1}$, H. Zeglaoui ${ }^{1}$, E. Bouajina ${ }^{1}$ ${ }^{1}$ Farhat Hached Hospital, Rheumathology, Sousse, Tunisia

Background: Spondylodiscitis (SD) is an infectious inflammation that affects the vertebrae, vertebral discs and adjacent structures. It may have a bacterial or non-bacterial etiology. Although analysis has improved and identification of pathogens is highly pursued, in one third of cases, no organism can be identified. Objectives: The objective of our work is to describe the epidemiological, clinica and evolutionary profile of SD with no germ identified and management.

Methods: This is a retrospective study including 37 cases of SD with no germ identified, collected in the Rheumatology Department of Farhat Hached hospital in Sousse, Tunisia over a period of 22 years (1998-2020).

Results: The mean age was 59.7 years [18-97 years]. These were 21 men (56.76 $\%)$ and 16 women (43.24\%).Spinal pain was the major symptom. The lumbar location was the most frequent in $56.76 \%$ of cases. It was a multifocal localization in $21.62 \%$. The imaging allowed the detection of para abscesses -vertebral in 43.24\%. An epiduritis was objectified in $54.05 \%$.CT-guided biopsy was performed in $59.46 \%$ and it was not conclusive. A bacteriological survey was carried out and came back negative. Spondylodiscitis was presumed to be tubercular and staphylococcal in respectively $62.16 \%$ and $18.92 \%$. The tuberculosis origin was retained in view of the chronic evolution, the multi-stage damage in the radiological assessment. While staphylococcal SD was retained due to the presence of cutaneous lesion and subacute evolution. Large-spectrum antibiotic therapy was initiated in the other cases.One case was initially considered to be staphylococca but with epidural and soft tissue extension tuberculosis was then considered to be the cause. The evolution after initiation of adequate antibiotic treatment was interspersed with neurological complications in one case of tuberculosis SD.

Conclusion: Our results show a higher frequency of presumed tuberculosis SD consider ing the endemicity of our country and the improvement under anti tuberculosis treatment REFERENCES:

[1] Cornett, C. A., and al. Bacterial Spine Infections in Adults. Journal of the American Academy of Orthopaedic Surgeons, 24(1), 11-18.(2016)

[2] Lener, S., and al Management of spinal infection: a review of the literature. Acta Neurochirurgica, 160(3), 487-496.(2018)

[3] Homagk, L., and al SponDT (Spondylodiscitis Diagnosis and Treatment) spondylodiscitis scoring system. Journal of Orthopaedic Surgery and Research, 14(1).(2019)

Disclosure of Interests: None declared

DOI: 10.1136/annrheumdis-2021-eular.3649

\section{\begin{tabular}{|l|l}
\hline POS1284 FASCIAL ULTRASOUND: THE CONTEXT FOR DRY \\
\hline
\end{tabular} NEEDLING TRIGGER POINTS IN TREATMENT OF MYOFASCIAL PAIN, POSTURAL IMBALANCE}

R. Bubnov ${ }^{1}$, L. Kalika ${ }^{2}{ }^{1}$ Clinical Hospital "Pheophania”, Ultrasound, Kyiv, Ukraine; ${ }^{2}$ NYDNRehab: Physical Therapy Clinic \& Chiropractic NYC Rehabilitation, New York, United States of America

Background: Muscles and fascia are the major source of pain in rheumatic diseases. Dry needling under ultrasound guidance (DN-US) is a crucial therapeutic approach to treat muscle pain [1,2], the definition 'myo-fascial' calls for searching trigger points (TrPs) in fascia to improve the treatment effectiveness.

Objectives: Aim was to evaluate the relevance of fascial ultrasound for DN-US in myo-fascial pain.

Methods: We included 36 patients (21 females, 20-69 years old) with myofascial pain different localisations (low back, limbs, shoulder, neck pain), postural imbalance; did DN-US protocol according to R. Bubnov [1]: trigge points were identified according, fine (28G) steel needle DN-US was applied. Additionally considered fascial structures for detecting areas of abnormalities (hypervascularity, heterogeinity, hypomotility, adhesions) aka 'trigger points and potental nerve compression/irritation and did precise DN-US where appropriate.

Results: In all patients movement restored and pain decreaed after muscles $\mathrm{DN}$; in 30 patients additionally we detected and did successful DN-US the 
major fascial points as follows: thoracolumbar fascia, sacroiliac joint, pelvis ligaments, rotator cuff; potential nerve compressions (e.g., arcade of Frochse, soleus arcade); nerve sheath surrounding nerves (sciatic nerve, brachial plexus) and vessels (thoracic outlet syndrome), smaller fascia, joint capsule thickening. We detected higher rates of motility, improvement postural balance and pain decrease, fewer sessions needed in patients after extensive protocol.

Conclusion: Fascia dry needling is accessible and effective method for myo-fascial pain treatment, may provide additional mechanical benefit and help to maintain treatment effect. Affected fascia can be considered as relevant trigger points, specific ultrasound symptoms should be validated.

REFERENCES

[1] Bubnov R Trigger Points Dry Needling Under Ultrasound Guidance for Low Back Pain Therapy. Comparative Study. Annals of the Rheumatic Diseases2015;74:624. http://dx.doi.org/10.1136/annrheumdis-2015-eular.2323

[2] Bubnov R, Kalika L, Babenko L. Dynamic ultrasound for multilevel evaluation of motion and posture in lower extremity and spine. Annals of the Rheumatic Diseases 2018;77:1699. http://dx.doi.org/10.1136/annrheumdis-2018-eular.3949

Disclosure of Interests: None declared

DOI: 10.1136/annrheumdis-2021-eular.3843

\section{POS1285 1 FOOT DISORDERS AND FALLS RISK IN OLDER PERSONS}

N. Fani ${ }^{1}$, E. Toulgui ${ }^{1}$, D. Khalifa ${ }^{2}$, S. Mtaoua ${ }^{3}$, W. Ouanes ${ }^{1}$, S. Jemni ${ }^{1}{ }^{1}$ Hôpital Sahloul, Physical Medicine and Rehabilitation, Sousse, Tunisia; ${ }^{2}$ Hospital Farhat Hached, Rhumatologie, Sousse, Tunisia; ${ }^{3} \mathrm{Hospital}$ Ibn El Jazzar, Physical Medicine and Rehabilitation, Kairouan, Tunisia

Background: Falls are major problems in older people, leading to serious morbidity and mortality. Many studies have identified intrinsic and extrinsic fall risk factors in order to develop preventive strategies and guidelines. There are few reports which studied the impacts of aging feet on falls [1].

Objectives: The present study aimed to explore foot musculoskeletal disorders and their relationship to falls in a healthy aging population.

Methods: This was a cross-sectional descriptive study involving the patients aged 65 years and over who were independent in self-care and walking followed at the physical medicine and rehabilitation department of the university hospital of sousse over 3 months. The analysed data focused on the epidemiological and clinical characteristics. Trained physicians evaluated health status, foot problems, and fall(s) history of all subjects. Walking performance was assessed using the 'Timed Get Up \& Go' test and the unipedal stance test was used for the assessment of balance. Footprints were taken from the standing position. Associated factors of foot disorders and falls were analyzed.

Results: There were 45 subjects: 18 men, 27 women with a mean age of 69.6 [6586 ] years. Foot deformities presented in $87 \%$ and were a significantly associated with walking performance or falls $(p=0.01, p=0.02)$. The most common foot musculoskeletal disorder were Halux valgus $31 \%$, followed by Mallet toe $15 \%$. Arch of foot classified by physical examination revealed that pes planus was presented in $35 \%$ of cases. There was a significant correlation between BMl and an arch index $(p=0.04)$. Foot problems remained significantly associated with impaired timed up and go test and the unipedal stance test. The causes of pain were plantar fasciitis, hallux valgus, callus, metatarsalgia, and inappropriate footwear. Falls were reported in 33.3 of patients. Falls were significantly associated with Hallux valgus, mallet toe and pain $(p<0.05)$.

Conclusion: Independent of the influence of age, gender, common conditions; foot problems have a significant impact on the ability to perform functional tasks integral to independent living.

\section{REFERENCES:}

[1] Menz HB, Lord SR: Foot problems, functional impairment, and falls in older people. J Am Podiatr Med Assoc 1999;89:458- 467. 3 Americ

Disclosure of Interests: None declared

DOI: 10.1136/annrheumdis-2021-eular.3918

\section{POS1286 \\ SHORT-TERM AND MID-TERM EFFICACY OF CAUDAL EPIDURAL STEROID INJECTIONS IN THE MANAGEMENT OF DEGENERATIVE SCIATICA}

D. Khalifa ${ }^{1}$, N. El Fani ${ }^{1}$, R. Moncer ${ }^{1}$, E. Toulgui ${ }^{1}$, W. Ouanes ${ }^{1}$, S. Jemni ${ }^{1}$

${ }^{1}$ Sahloul Hospital, Physical Therapy and Rehabilitation, Sousse, Tunisia

Background: Epidural steroid injections are largely used in the management of osteoarthritis-related sciatica. Three possible sites of injection are possible: the caudal through the sacral hiatus, the interlaminar and the transforaminal site. The caudal technique is known to be the most simple one. However, doubts still persist about this infiltration's efficacy.

Objectives: The aim of this work was to study the short-term and mid-term efficacy of caudal epidural steroid injections in patients suffering from sciatica related to a degenerative etiology and to study the determining factors of its efficacy.
Methods: A retroscpective, descriptive and monocentric study was conducted in Sahloul university hospital of Tunisia. Medical records of patients who suffered from sciatica due to disc herniation or spinal stenosis were analysed. Only patients who benefited from at least one caudal epidural steroid injection were included. Other etiologies were ruled out by CT-scan or MRI and laboratory tests. Efficacy of the injection was evaluated by the visual analog scale of pain (VAS) at the first week post infiltration, 3 months and 6 months later. The infiltration was considered effective if the difference of pain scoe by VAS was $\geq 50 \%$ compared to baseline's score. The presence of anxiety and depression was also tracked down with the hospital anxiety and depression scale. Data was collected and analysed using the statistical tool SPSS.20.

Results: Twenty-five patients were included. They were 7 males and 18 females. The mean age at diagnosis was $51.88 \pm 15.28$ years. Eleven patients had another osteoarthritis site. Five patients had previous back surgery: 2 dissectomies, 1 arthrodesis, and 2 laminectomies. Median duration of sciatica was 30 months. Sciatica was bilateral in $41.7 \%$ of the cases, impulsive during efforts in $52 \%$ of the cases and with claudication in $92 \%$ of the cases. The median VAS score at baseline was 7 out of $10(\min =4 ; \max =9)$. All patients had tried medical treatment using NSAIDS and painkillers, and physical therapy before prescribing the infiltration. The technique was similar in all patients: Lidocaine $1 \%$ was first injected at a median volume of $5 \mathrm{ml}$, followed by corticosteroids and finally a saline solution (median volume of $20 \mathrm{ml}$ ). The median number of epidural caudal injections was 3 injections $(\min =1 ; \max =3$ ). The caudal epidural steroid injections were effective in $60 \%$ of the patients at the first week, $56 \%$ in the cases at 3 months and $56 \%$ of the cases at 6 months. Factors associated with efficacy of the injection at the first week were greater total volume injected $(p=0.001)$, and greater saline solution volumes $(p=0.016)$. At 3 months, factors significantly associated with efficacy of the infiltration were having unilateral pain $(p=0.05)$, a positive straight leg raise test sign $(p=0.028)$, a lower anxiety score $(0.014)$ and a lower depression $(0.000)$ score. At 6 months, factors associated with efficacy were not having cervical osteoarthritis $(p=0.03)$, unilateral pain $(p=0.05)$, low anxiety $(p=0.014)$ and low depression $(p=0.001)$ scores and a higher number of steroid injections $(p=0.05)$ Conclusion: Caudal epidural steroid injections seem effective on the short-term and this efficacy is maintained till the mid-term. Greater volumes may help with pain by possible adhesiolyse-like mechanisms and having unilateral pain, positive straight leg raise sign, a higher number of injections, no anxiety or depression and no other osteoarthritis sites makes the infiltration more effective.

\section{REFERENCES:}

[1] Dincer U, Kiralp MZ, Cakar E, Yasar E, Dursan H. Caudal epidural injection versus non-steroidal anti-inflammatory drugs in the treatment of low back pain accompanied with radicular pain. Joint Bone Spine. 2007;5.

Disclosure of Interests: None declared

DOI: 10.1136/annrheumdis-2021-eular.3967

\section{POS1287 ANXIETY, DEPRESSION, FIBROMYALGIA SYNDROME AND PAIN INTENSITY IN PATIENTS WITH LOW BACK} PAIN

R. Dhahri ${ }^{1}$, A. Dghaies ${ }^{1}$, M. Slouma ${ }^{1}$, L. Metoui ${ }^{1}$, I. Gharsallah ${ }^{1}$, I. Dorgham ${ }^{2}$, R. Ayari ${ }^{2}$, Y. Mallat ${ }^{2}, \mathrm{~K}$. Amri ${ }^{2}{ }^{1}$ The Military Hospital of Tunis, Rheumatology, Tunis, Tunisia; ${ }^{2}$ The Military Hospital of Tunis, Traumatology-Orthopedic Department, Tunis, Tunisia

Background: Common low back pain (LBP) is a common health problem affecting 50 to $80 \%$ of working age adults resulting in significant personal, social and occupational impairment. Chronic pain has a negative impact on quality of life and psychological well-being.

Objectives: The aim of this study was to examine the relationship between anxiety, depression and pain intensity in patients with low back pain in a population made of military agents.

Methods: It was an analytical cross-sectional study including 50 patients with at least three months of LBP, in the department of rheumatology and orthopedics at the Military Hospital of Tunis between January 1st and March 31, 2020. Al patients had a standardized clinical assessment. Patients completed the «hospital anxiety and depression scale» (HADS) and the «Fibromyalgia Rapid Screen ing Tool» (FIRST) to evaluate psychological impact of chronic LBP. Pain intensity was assessed using a visual analog scale (VAS)

Results: The mean age of the patients was $41.9 \pm 8.4$ years and the sex ratio was 4.5 . LBP duration was 66.4 months. The mean lumbar visual analog scale (VAS) was $4.5 \pm 1.9$, and the root VAS was $2.6 \pm 2.5$. Neuropathic pain was found in $26 \%$ of patients. Abnormal level of anxiety and depression were found in $58 \%$ and $62 \%$ of the patients respectively. Out of them $20 \%$ and $26 \%$ were borderline abnormal for anxiety and depression respectively, while $38 \%(16.4 \%)$ and $36 \%$ were certainly abnormal for anxiety and depression respectively. Twelve percent of the patients had fibromyalgia syndrome associated with LBP as they had a FIRST score $\geq 5$. Positive correlations were found between lumbar VAS and HAD anxiety/depression scores $(r=0.35 ; p<0.01 / r=0.3 ; p=0.04)$. Positive correlations were also found between root VAS and HAD anxiety/depression $(R=0.38$; 